\title{
¡Oh místico, sagrado sol! en el colegio de San Juan y San Pedro: sermón a las exequias de Manuel Fernández de Santa Cruz, Obispo de Puebla. Retórica y simbolismo*
}

Wendy Lucía Morales Prado Universidad Nacional Autónoma de México

A la Dra. María Dolores Bravo, sol universitario

La religión es un ámbito relacionado con la muerte. Es decir, si no muriéramos, no seríamos religiosos. Sỉ no fuéramos dependientes, nuestros cuerpos falibles, si no nos enfermáramos, no habría religión. La religión tiene un aspecto básico dentro de la vida de la gente, que es darle esperanza ${ }^{1}$.

En la cultura barroca existen diversos modos de vivir el misterio de Dios. Diferentes formas en las que esta experiencia se vuelve pal-

* Versión corregida y aumentada de la ponencia presentada en el Coloquio Internacional EI misticismo iberoamericano: siglos XVI-XVIII, organizado por e] Instituto de Investigaciones Históricas de la Universidad Nacional Autónoma de México y el Centro de Estudios de Historia de México CARSO. (México, D.F., 8-10 de junio de 2011).

1. Antonio Rubial García en Discutamos México, programa 6: "Religión y costumbres en el México Colonial”, Gobierno Federal-Canal Once, México, 2010. 
pable. Algunas sublimes, otras placenteras, violentas, dolorosas; todas extremas intentan transmitir el sentido y la experiencia de lo inefable. Como todos sabemos, la importancia de la Iglesia en la Nueva España era fundamental y su labor por excelencia era la prédica homilética. En la producción impresa del virreinato hubo una importante cantidad de sermones publicados, tanto en ocasión de alegres celebraciones, como en circunstancias tristes y solemnes, organizadas por el poder eclesiástico y/o civil. Había incluso sermonarios que facilitaban la labor de los panegiristas, por lo que no es raro que hoy en día tengamos un auténtico

...maremágnum de 2000 piezas oratorias publicadas en Nueva España... el $57 \%$ corresponde a sermones panegíricos donde... el sermón fúnebre, de honras o exequias representa $24 \%$ del total de la oratoria impresa. Aunque los ornamentos fueran negros y el tono elegíaco, el sermón fúnebre asumía algunos rasgos del panegírico. Salvo el defecto de la ausencia, no se iban a ponderar otras faltas o pecados del difunto, sino sus bien ganados o supuestos méritos².

La muerte, desde tiempos inmemoriales, adquiere una importancia decisiva dentro de las sociedades, pues manifiesta ideas relativas al entendimiento de la vida, al legado del difunto. Es, entonces, todo un mensaje cifrado que interpela a los que quedan del otro lado, en la vida. "Alrededor de este acontecimiento culminante de la muerte existe no sólo un fenómeno de percepciones y culturas, sino figuras y modismos arquetípicos del lenguaje humano con una inmensa corte de paradojas, ritos y mitos. La muerte es la noticia más importante de la vida" ${ }^{3}$.

2. Carlos Herrejón Peredo, Introducción a Del sermón al discurso cívico, 1760 1834. México, El Colegio de Michoacán-El Colegio de México, 2003, p. 19. A este juicio lo apoyaba la cita latina: De mortuus nihil nissi bonum "de los muertos no decir sino lo que les favorezca".

3. Eulalio Ferrer, El lenguaje de la inmortalidad. México, Fondo de Cultura Económica, 2003, pp. 17-18. 
Los sermones, recordemos, formaban parte de la vida social en comunidad y eran indispensables en la formación de todo novohispano:

Junto con la música, el sermón ocupaba un lugar especial en el gusto de los fieles que asistían a las ceremonias... el púlpito era... una palestra para la información, la apología o la denuncia. Además de las misas solemnes, la administración de algunos sacramentos, como el matrimonio, la ordenación sacerdotal, las exequias fúnebres o la toma de hábito y votos, eran también ocasiones propicias para el despliegue de estos elaborados artificios verbales ${ }^{4}$.

Los sermones fúnebres, túmulos y catafalcos son ejemplos del ceremonial con el que la Iglesia católica rubricaba una vida hasta el fin. Por el rito litúrgico de la misa de cuerpo presente, el difunto nacía a la vida eterna. Por otro lado, mediante los sermones se proclamaba un mensaje dogmático, útil a la sujeción de los vivos, que daba significado y re-significación al dolor por la pérdida de un ser querido.

La fiesta, entendida como un aparato de representación del poder novohispano donde confluían todas las clases sociales, juntas pero no revueltas, conocía diversas manifestaciones. Existían festividades religiosas a lo largo de todo el calendario litúrgico, que se combinaban con las celebraciones y conmemoraciones civiles. Había fiestas cíclicas y excepcionales. Algunas eran de jolgorio y explosión festiva. Y existían también, representaciones de "doloroso aparato", en las que, desde luego, el sentido de fiesta no evoca un sentimiento de júbilo, sino una tristeza infausta que en un solo sentido convocaba a una multitud:

Las ceremonias fúnebres, con que los vivos pretenden enaltecer la figura de sus muertos resultarían incompletas si no fuesen precedidas por un extraño proceso de perdón y tolerancia colectivos, activado de manera

4. Antonio Rubial García, Monjas, cortesanos y plebeyos. La vida cotidiana en la época de Sor Juana. México, Taurus, 2005, p. 176. 
espontánea desde el momento que fallece el personaje en cuestión para que su nombre y prestigio queden aparentemente limpios o exaltados... las exequias se convirtieron en el trance idóneo para que operase este contrato social de apoyo y perdón comunitario que consiste en sublimar la imagen del difunto, de tal manera que quede grabado en la memoria de todos su buen nombre ${ }^{5}$.

Este tipo de representaciones tienen un marcado carácter urbano. La ciudad de Puebla era un gran centro, con población masiva que respondía a la convocatoria que fusionaba ideales colectivos, verdaderos valores comunes a partir de los cuales se fusionaba la sociedad en un verdadero cuerpo de individuos y congregaciones operando juntos para un solo fin. Ese espacio propicio, era la ciudad. A este respecto, tenemos una valiosa aportación de María Dolores Bravo:

La indudable cualidad no sólo espacial sino sobre todo ideológica que las grandes ciudades tienen como "teatro", como escenario del poder y como símbolos que éste manifiesta para ser representado y venerado. En ellas residen los ejes bifrontes del poder que el monarca hispano confiere a sus enviados: el arzobispo como representante de su personalidad por ser patrono de la Iglesia y el virrey y la Audiencia como ejecutores del poder civil. La ciudad es, pues, a través de todas sus instituciones, el centro real y simbólico donde se manifiesta la autoridad invisible pero todopoderosa del soberano que lo es por designio divino ${ }^{6}$.

Probablemente la más importante de las conmemoraciones solemnes y dolorosas a la muerte dentro del calendario litúrgico era la Semana Santa, un auténtico luto de dimensiones magnificadas. Se pretendía introyectar la presencia de la muerte como

5. Eulalio Ferrer, op. cit., p. 149.

6. "Textos diversos de festejos novohispanos del siglo XVI", en Fiesta y Celebración: Discurso y espacio novohispanos. Ed. de María Águeda Méndez. México, El Colegio de México, 2009, p. 42. 
ejercicio de la humildad absoluta, renuncia a las frivolidades del mundo y mortificación ofrecida en nombre del sacrificio de Cristo en la cruz. También era un recordatorio de la esperanza cierta de la resurrección.

Otras representaciones mortuorias se daban cuando un personaje importante de la sociedad (arzobispo, obispo, virrey) cambiaba su estatus terrenal por el trascendente. La partida de este mundo supone, en las sociedades humanas, un inmediato cambio de status: "la muerte es una palabra que resume a las que gobiernan, en gran parte, los momentos claves de la existencia, con su culminación final: una ceremonia que consagre" .

En este trabajo analizaremos un sermón a las exequias del ilustre obispo poblano, Manuel Fernández de Santa Cruz, español nacido en Palencia en enero de 1637, colegial mayor en Cuenca, canónigo magistral en la iglesia de Segovia, promovido a Nueva España como obispo electo de Chiapas - cargo que no ejerció-, Obispo de Guadalajara, y una vez en Puebla de los Ángeles presidió la diócesis en 1676. Muere en 1699 a la edad de 76 años.

Fernández de Santa Cruz figura en el firmamento literario por su seudónimo de Sor Filotea de la Cruz. En una carta que Sor FiloteaDon Manuel envía a Sor Juana Inés de la Cruz la insta a dejar las letras profanas. Gracias a los "piadosos" regaños de don Manuel, es que Sor Juana responde en un documento autobiográfico muy importante - y uno de nuestros mejores ejemplos de prosa barroca- la Respuesta a Sor Filotea de la Cruz.

Sor Juana en la ciudad de México, muere en abril de 1695; Sor Filotea, o sea don Manuel, en 1699 en una visita pastoral en el pequeñísimo pueblo de Tepexoxuma. Aunque enfermo al final de sus días, ni así dejó de recorrer los poblados más alejados de su diócesis poblana, el segundo obispado más rico de Nueva España ${ }^{8}$.

7. Eulalio Ferrer, op. cit., p. 149.

8. Leonardo Lomelí Vanegas, "La segunda ciudad del virreinato", en Breve historia de Puebla. México, El Colegio de México-Fondo de Cultura Económica, 2001, p. 76. 
Las honras fúnebres del obispo Fernández de Santa Cruz, vertidas asimismo en relaciones de $\operatorname{sucesos}^{9}$ son paradigma de la fastuosidad barroca:

Su cuerpo fue embalsamado porque los obispos han sido ungidos y así lo marca el ritual. Murió el 1 de febrero de 1699 y su entierro se dispuso hasta el 5. En la procesión se colocaron hasta adelante 24 pobres con lobas de bayeta negra que les dieron y cirios en las manos; se pusieron nueve pozas en el camino a la catedral, y en cada una se turnaron los que cargaban el cadáver. Se le puso sobre un túmulo de 200 luces y dio principio la vigilia. Se le enterró en la bóveda que se construyó para obispos bajo el presbiterio de Catedral. La bóveda tiene un lugar principal en medio donde se pone el ataúd hasta que va a ser enterrado otro obispo; entonces se le pasa a un nicho especial. Después siguió el novenario y las honras, para estas últimas hubo oración y sermón fúnebre; con esto se clausuraron las exequias. Aunque después las diferentes órdenes religiosas le siguieron celebrando honras en sus respectivos conventos ${ }^{10}$.

Hoy Puebla es una de las ciudades coloniales más representativas y un estado con una riqueza gastronómica privilegiada, entre otros muchos atractivos. Su atractivo viene de siglos anteriores;

9. Se conservan en total seis sermones fúnebres dedicados a Fernández de Santa Cruz, uno de ellos es el que aquí se analiza. Las relaciones de sucesos están en el sermón predicado en la Catedral, de Joseph Gómez de la Parra, titulado Panegýrico Funeral de la vida en la muerte del Illmo. y Excmo. Señor. Dr. Don Manuel Fernández de Santa Cruz, Obispo de la Puebla de los Ângeles en la Nueva España..., y dentro de él se encuentra la relación de sucesos "Relación narrativa de la enfermedad, muerte, entierro y honras funerales de su Excelencia". El presbítero Miguel de Torres, retoma casi textualmente esta relación en su biografía hagiográfica dedicada al mismo evento, el Dechado de Príncipes Eclesiásticos, que dibujó con su ejemplar, virtuosa y ajustada vida el Illmo., y Excmo. Señor Doctor D. Manuel Fernández de S. Cruz y Sahagún. Un excelente análisis de estas relaciones de sucesos es el de María Dolores Bravo, "Metáfora del dolor: exequias en honor de Sor Filotea de la Cruz", en Ensayos sobre literaturas y culturas de la Nueva España. Ed. de Mariana Masera y Enrique Flores. México, UNAM, 2009, pp. 205-216.

10. María de los Ángeles Rodríguez Álvarez, Usos y costumbres funerarios en Nueva España. Toluca, El Colegio de Michoacán-El Colegio Mexiquense, 2001, p. 226. 
en el siglo XVII rivalizaba abiertamente con la ciudad de México, y en esta etapa de esplendor estuvo Fernández de Santa Cruz como importante actor y promotor de "el angelitano obispado":

Puebla durante la época colonial fue uno de los grandes centros culturales, artísticos, religiosos y económicos de México. El epíteto de "relicario de América" con que alguna vez se le caracterizó no es exagerado. Paso obligado entre México y Veracruz, cabe decir, entre Europa y Nueva España, en Puebla confluyeron diversas corrientes culturales que le dieron un carácter único. Ahí fue donde se estableció la segunda imprenta de México y la tercera de la América española ${ }^{11}$.

\section{Fernández de Santa Cruz se caracterizó por un celo excepcio-} nal, numerosas obras y fundaciones ${ }^{12}$, defensa de su diócesis ante la voracidad de la ciudad de México (impidió el traslado de grano poblano a la capital ${ }^{13}$ ), cuidadoso y amoroso pastor en tiempos de epidemias ${ }^{14} \mathrm{y}$ hasta defensor de la graduación por suficiencia académica de los estudiantes poblanos de teología, ya que la Real Universidad de México monopolizaba este procedimiento: "aquella

11. Elías Trabulse, Prólogo a Cien impresos coloniales poblanos. México, Instituto José María Luis Mora, 1991, p. 10.

12. Entre las fundaciones, se cuentan la fundación de dos colegios de vírgenes, la casa para mujeres recogidas, la fundación de un colegio para niñas (luego convento de Santa Mónica), el colegio de los infantes, el colegio máximo de San Pablo y el colegio de Jesús María; Fray Miguel de Torres, Dechado de Príncipes Eclesiásticos, que dibujó con su ejemplar, virtuosa y ajustada vida el Illmo. y Excmo. Señor Doctor D. Manuel Fernández de Santa Cruz y Sahagún. Edición facsímile de la obra original. México, Sociedad Mexicana de Bibliófilos, 1999.

13. Léase el apartado "Defiende con valor y constancia, contra orden superior, que no saquen las semillas de su obispado para conducirlas a México, en perjuicio de su rebaño", en ed. cit., f. 254.

14. Léase el apartado "Continua su piedad en la peste general: hace hospicio de enfermos, señala botica y médicos a costa de su liberalidad", ibid., f. 261. Respecto a las epidemias en Puebla, se sabe que la más terrible de todas fue la del matlazahuatl, en la primera mitad del siglo XVIII, aunque hubo otras epidemias anteriores. Para información específica al respecto, véase el interesante estudio de Miguel Ángel Cuenya, Puebla de los Ángeles en tiempos de una peste colonial. México, El Colegio de Michoacán-Benemérita Universidad Autónoma de Puebla, 1999. 
Universidad que solamente atiende al número y no al aprovechamiento de los estudiantes" ${ }^{15}$, en palabras de don Manuel.

¿Cómo se vivía la experiencia divina en un colegio real? ¿Cómo ponderar la muerte de un prelado benefactor? ¿Qué virtudes y qué símbolos utilizar? Seguramente, estas preguntas pasaron por la mente del bachiller Francisco Antonio de la Cruz, a quien se le encomendó un sermón fúnebre a nombre del colegio real de San Juan y San Pedro, fundado por el obispo Juan de Palafox y Mendoza.

El texto se titula: Declamación fúnebre que en las exequias, que consagró a su amabilíssimo pastor, ilustríssimo y excelentíssimo Señor Doctor Don Manuel Fernández de Santa Cruz, el Colegio Real de San Juan y San Pedro: Dixo en la Iglesia de Santa Vera-Cruz y oratorio de Nuestro Padre San Phelipe Neri, el día 28 de Febrero del año de 1699. El Bachiller Francisco Antonio de la Cruz, cura beneficiado por su Majestad, vicario y juez eclesiástico del Pueblo y partido de San Francisco de Apango. Dedícalo al Licenciado Don Christóbal Dávila, Galindo, y Esquibel, Tezorero de dichos Reales Colegios, Mayordomo, y Administrador de sus rentas. Con licencia: En la Puebla, en la imprenta de los Herederos del Capitán Juan de Villa Real en el Portal de las flores ${ }^{16}$.

El bachiller de la Cruz — quien a la sazón era cura beneficiado por su majestad, vicario y juez eclesiástico del pueblo de San Francisco de Apango- - dedicó el sermón al tesorero de esos reales colegios. Entre falsa modestia y verdadera cortesanía (otro importante concepto sólo posible en una urbe, en la cual, ciertamente, no había otro personaje más allegado a la realeza que el mismo obispo) relata que la empresa se debe a la "obediencia: no con arrojos de presumida, sino con encogimientos de resignada". Y que fía a las prensas sus "breves borrones de estos mal limados discursos", pero se confió del parecer ajeno porque vivió "poco enamorado de [su] dictamen propio". Sólo este "intelectual sacrificio" e "hijo de su en-

15. Elías Trabulse, op. cit., carta del 17 de enero de 1679, dirigida al presidente del Consejo de Indias.

16. En la transcripción se conserva la ortografía original del documento y se desatan las abreviaturas. Sin embargo, en las citas textuales modernizo la ortografía para una ágil lectura. 
tendimiento" vale por estar patrocinado por el tesorero del colegio y dedicado al fallecido obispo don Manuel.

De tal suerte que "estos abortivos discursos y mal formados conceptos" tomarán prestado el lustre de las prendas del tesorero del colegio a quien, además, dedica un largo encomio a su linaje. No podía ser de otra manera, pues la actitud valorativa del hablante hacia el momento de emitir un sermón fúnebre es de honor y agradecimiento. El elegido suele ser una persona cercana al difunto, que lo conoció y a quien los presentes asocian como alguien cercano, de buen juicio y adecuada preparación. El momento del sermón era esperado por los asistentes en la misa y se criticaba severamente la elocución del predicador. "En las grandes capitales el público tendía a ser exigente. De aceptarse el dicho habitual entre predicadores, la gente estaba ya tan acostumbrada a juzgar la calidad y ejecución de los sermones, que no había manera de dormirse en los laureles"17.

En el sermón se percibe una sociedad eminentemente corporativa. Si es posible, trataremos ahora de desenmarañar el complejo entramado de la sociedad poblana de finales del siglo XVII: unos encargan a otros (Joseph de la Parra, catedrático de prima en los Reales Colegios - promovidos por el difunto- quien predicó el sermón en Catedral, maestro de Francisco Antonio, le encarga el sermón y escribe su parecer); otros se apoyan en terceros (Francisco Antonio, como alumno destacado, da voz a toda la congregación de alumnos y claustro académico, y enumera diversos nombres y sus cargos; no están de más las aprobaciones, que sirven como referencia de auténticas redes de apoyo institucional); también agradecen (el orador al encargo de su maestro, su escuela y los favores del tesorero, pues son "muchos motivos que ejecutan mi voluntad y grandes obligaciones, que embargan mi gratitud... me confieso excedido en el recibo de continuados favores" ${ }^{18}$ ), inquieren (el ser-

17. Manuel Morán y José Andrés-Gallego, "El predicador", en El hombre barroco. Ed. de Rosario Villari. Madrid, Alianza, 1992, p. 186.

18. Francisco Antonio de la Cruz, "Dedicatoria al Lic. Christóbal Dávila Galindo y Esquibel", en Declamación fúnebre, que en las exequias... Puebla, Herederos del Capitán Juan de Villa Real, 1699, f. 5r. 
món está dedicado al tesorero de los colegios, de quien el bachiller de la Cruz pide "suplico a Vuestra merced, acoja benigno este corto tributo" ${ }^{19}$ ) y todos juntos, en doliente sentimiento de ausencia, se encomiendan a uno (a la virgen, en este caso "la estrella hermosa del mejor norte" $\left.{ }^{20}\right)$.

Se busca el amparo: el individuo por sus fueros, no existe y sólo alcanza voz gracias a la importancia de la comunidad a la que pertenece. La ciudad de Puebla de los Ángeles alcanza así un grado de representatividad colectiva palpable en este periodo, como no se volverá a ver después del virreinato.

En la salutación, el padre de la Cruz evoca la tenebrosa naturaleza oscura y, para esto, parece parafrasear el Primero Sueño de Sor Juana:

¡Qué tristes se representan las esferas con la ausencia de la luz! ¡Que melancólicos se reconocen los hemisferios con la falta del sol! Apenas a nuestros ojos se trasmonta ese lucido planeta, cuando comienza en fúnebre desaliño a desencuadernarse la armónica compostura de todo ese vistoso y bien artificiado volumen del universo, mustias las plantas y marchitas las flores conmutan en lánguidos desmayos la culta gallardía de sus verdores, la fragante pompa de sus aromas, la nativa fineza de sus carmines. Los árboles que, a cuenta de su elevada estatura de la desmedida grandeza con que embarazaban el aire, o se presumían vegetales obeliscos, o se ufanaban verdes pirámides, son ya confuso asombro de la campaña, inútil embarazo del viento, formidable objeto a la vista. Las aves, que en dulces acentos y métricas consonancias divertían el sentido o lisonjeaban el gusto, callan enmudecidas en profundo silencio y sepultadas en torpe letargo. Las fieras republicanas del bosque, ocupadas de la confusión y el espanto, se acobardan medrosas y se retiran confusas. Aun los arroyos insensibles, si no pausan el intrépido torrente de sus cristales, el arrebatado curso de sus aljófares, o se fingen al sentido menos sonora, o se mienten a la idea más destemplados. El aire descoge negros lutos de dolor, en atezadas sombras de obscuridad y desembarazado del comercio de tanta viviente pluma, solo

19. Ibid., f. 10r.

20. Ibid., f. 3v. 
se ve asistido de la confusa turba de nocturnas aves, gimiendo tristes y volando graves. Finalmente toda la naturaleza se baraja a sentimientos porque toda se conmueve a quebrantos... pues lo que sucede en el ocaso de este planeta material, es lo que hoy experimenta nuestro dolor en la muerte del sol místico de este hemisferio angélico ${ }^{21}$.

El bachiller de la Cruz cita textualmente además versos de la Fábula de Polifemo y Galatea de Góngora "la confusa turba de nocturnas aves, gimiendo tristes y volando graves". Toda la oscuridad mueve a tristeza y de aquí hace la analogía que será el tema: "pues lo que sucede en el ocaso de este planeta material, es lo que hoy experimenta nuestro dolor en la muerte del Sol místico de este hemisferio". En la referencia queda manifiesta la fecundación que pasaba desde el discurso profano hacia el texto religioso. Poesía y homilética se alimentaban mutuamente en la Puebla de finales del siglo XVII, pues en la dispositio el autor recurre a un texto literario ampliamente conocido, del cual se vale para darle profundidad y un sentido estético a su sermón.

Y a continuación viene la patética exclamación con un fuerte tinte teatral de reticencia:

Murió (si puede llamarse muerte a la que permutó a más permanente vida) murió (va a pronunciarlo la lengua y la embaraza el dolor) murió (digámoslo de una vez y apuremos todo el veneno al vaso). Murió el Ilmo. Revmo. y Excmo. Sr. Dr. Don Manuel Fernández de Santa Cruz, Sol Místico, que con la eficacia de sus luces y con la beneficencia de sus influjos, alumbró a todo el angelopolitano obispado ${ }^{22}$.

Todos los maestros del colegio son estrellas "con luz de doctrina" que guían al orador quien, asimismo, sigue a la estrella más luciente: la virgen María para llevar a buen puerto su empresa oratoria.

21. Ibid., f. I $\mathrm{v}-2 \mathrm{r}$.

22. Ibid., f. $2 \mathrm{v}$. 
Existían ciertos elementos simbólicos iconizados hacia finales del siglo XVII para caracterizar a la nobleza y alcurnia eclesiástica: el sol como astro rey, dador de vida y luz de entendimiento; el oro, metal precioso e incorruptible, donde los rayos del sol habían quedado inmanentes. De los animales, el águila, que miraba de frente al sol y hacía su nido cerca de él. El pelícano, que se lastimaba el pecho con tal de ofrendar su sangre a sus polluelos. Sin embargo:

Desde la Edad Media se tenía como referencia el obispo ideal formulado ya en los primeros tiempos de la Reforma Católica y recordado incesantemente a través de los episcopologios o de las oraciones fúnebres, llenas de referencias del Antiguo Testamento o de la Antigüedad clásica ${ }^{23}$.

Recordemos a San Agustín, obispo de Hipona, por citar tan solo un ejemplo. La alusión a este modelo consistió en un alegato útil para aleccionar a la comunidad de feligreses y para criticar los vicios de un clero tibio. En el caso de las fuentes bíblicas, los obispos eran comparados con Aarón o Moisés ${ }^{24}$.

23. Arturo Morgado García, Ser clérigo en la España del Antiguo Régimen. Cádiz, Servicio de Publicaciones de la Universidad, 2000, p. 35.

24. En el Antiguo testamento son dirigentes, sumos sacerdotes y portavoces de la divinidad. En este sentido, son prefiguraciones de Cristo. Tienen rencillas entre sí y su trayecto con la divinidad no carece de pecados y castigos. Las referencias que funcionan como materia de alusión frecuente en los sermones son éstas: Aarón es hermano mayor por tres años de Moisés. Acompañó a éste cuando se presentó frente al Faraón y colaboró con él durante los cuarenta años del desierto (Ex. 6:20, 7:7; Num. 26:59). La primera vez que se habla de él es cuando Dios le dijo a Moisés que Aarón sería su vocero, Ex.4:14-16. Sostuvo las manos de Moisés en la batalla contra los amalecitas, $E x$. 17. En el Sinaí fue nombrado Sumo Sacerdote (Ex. 28), y sus hijos fueron consagrados para el sacerdocio (Lev. 8:9). Un sacerdocio hereditario. Sin embargo, comete un pecado terrible al hacer el Becerro de Oro, Ex. 22, del cual es perdonado por la súplica de Moisés, Deut. 9:20. Su autoridad, reivindicada por el milagro de la vara, Núm. 17. Sin embargo, es excluido, con Moisés, de entrar en la Tierra de Promisión, Num. 20:1. Murió con Moisés a su lado, y el Sumo Sacerdocio pasó a su hijo Eleazar, Num. 20:22, 33-38, Dt. 10:6, 32:50. En Hebreos 5:4 se presenta a Aarón como tipo de Cristo. En cuanto a Moisés, fue éste quien recibió directamente las instrucciones de Dios para el establecimiento de la nación de los hébreos como una teocracia ( $E x .24: 9-11 ; 33: 11,17-23 ; 34: 5-29$; etc.), incluyendo la ley básica de los Diez Mandamientos, que también fueron presentados en forma 
El razonamiento inductivo a base de comparaciones amplificatorias $^{25}$, típico del sermón, tenía una finalidad persuasiva, que amalgamaba y tornaba conductual una larga tradición erudita de referencias y alusiones clásicas, bíblicas, etc. Hábilmente manipuladas, de hecho "el sermón novohispano cumplía una función de intermediación cultural. Tratados teológicos y tradiciones del cristianismo, así como sabiduría pagana, eran abordados por igual" 26 .

El sermón fúnebre, por su carácter bíblico y referencias clásicas, evidencia una naturaleza intertextual inmediata.

El sermón fúnebre tiene dos protagonistas: la muerte y el difunto, que conforman el tema de la oración y la estructura del discurso en tres partes bien diferenciadas, si bien, íntimamente conexionadas: una primera parte, doctrinal, que sí dilata en consideraciones más o menos tópicas sobre la vida y la muerte; una segunda, de carácter panegírico, destinada a exaltar

oral ante la congregación (20:1-18). Como vocero de Dios, dirigió al pueblo a la relación del pacto que constituía a Israel como una teocracia $(E x .19: 5-8 ; 24: 3-8)$. Moisés, luego del evento del Becerro de Oro, demostró su estatura como líder, intercediendo fervorosamente en favor de Israel, y Dios los perdonó (vs 11-14). Después de haber castigado adecuadamente al pueblo (vs 30-35), Moisés una vez más buscó a Dios, quien le prometió: "Mi presencia irá contigo, y te daré descanso" (33:1217). Junto al monte Sinaí, episodio durante el cual Israel se constituyó en nación, se codificaron sus leyes, se construyó el tabernáculo y se organizó el culto; luego Israel salió hacia Canaán (Nm. 10:11-13). Poco tiempo después, María y Aarón desafiaron el liderazgo de Moisés $(12: 1,2)$ pero el Señor lo vindicó claramente como su portavoz designado. Moisés designó a Josué como su sucesor (Nm. 27:18-23; Dt. 1:38), y poco antes de su muerte lo llevó al tabernáculo para recibir su responsabilidad del Señor $(D t .31: 14,23)$. Luego, por indicación de Dios, ascendió el monte Nebo, donde contempló la tierra prometida (fig. 378) y murió a la edad de 120 años (Dt. 32:48-52; 34:7). Dios lo enterró allí (v 6), lo llamó del lugar donde descansaba (Jud. 9), y más tarde lo honró con Elías sobre el monte de la Transfiguración (Mt. 17:3, 4). A pesar de sus talentos superiores fue "muy manso, más que todos los hombres que había sobre la tierra" (Num. 12:3); Benjamin A. Millard, Diccionario bíblico abreviado. Madrid, San Pablo, 2000, pp. 37-157.

25. Helena Beristáin, Diccionario de Retórica y Poética. México, Porrúa, 1995, s.v. 'retórica'.

26. Carlos Herrejón Peredo, "El sermón novohispano", en Historia de la Literatura Mexicana. T. 2: La cultura letrada de la Nueva España del siglo XVII, Coord. de Raquel Chang-Rodríguez. México, UNAM-Siglo XXI, 2002, p. 431. 
los hechos y virtudes del personaje fallecido, y una tercera, que atañe a los que el muerto dejó en la orilla de acá de la frontera de la vida ${ }^{27}$.

Ahora bien, el tema es la analogía del obispo recién fallecido con el sol, ¿y cuáles son los beneficios del astro rey? El bachiller De la Cruz resalta dos, de donde vendrán sendos discursos a los beneficios de la luz y del calor. Así, pues, queda establecida la introducción y la división de asuntos a tratar. Ahora falta ajustar el tema al asunto dado, lo que va realizando en el cuerpo del sermón de acuerdo con lo siguiente:

Primer beneficio: la luz. Éste lo experimentó el real colegio con un acto singular, una verdadera "menudencia" 28 : ¿Cuántas veces iba en persona a despertar a los estudiantes para que se empleasen en la tarea de su obligación? En tantas ocasiones desmañanó estudiantes, "que no podrá numerarlas el guarismo, ni comprenderlas la aritmética"29. Aunque para De la Cruz esto era un verdadero sacrificio místico, pues iba don Manuel "madrugando solícito a imitación del Sol de justicia, a desterrar sombras de ignorancia y a introducir brillos de sabiduría" ${ }^{30}$.

El misticismo del obispo, cual sol, era levantar temprano a sus plantas de la juventud y en tiempo de exámenes, asistirlas con verdadera devoción en sus estudios. "Ese sí que es empeño de una solicitud más que humana, y empleo de una dignación divina... para alumbrar con sus luces y animar con sus brillos los tiernos pimpollos y delicados renuevos del ingenioso jardín de nuestra academia real" ${ }^{31}$.

Segundo beneficio: el calor, "con que fomentaba el progreso de las letras, el ardor con que solicitaba el aumento de las virtudes" ${ }^{32}$. Don

27. Félix Herrero Salgado, La oratoria sagrada en los siglos XVI y XVII. T. 3: La predicación en la Compañía de Jesús. Madrid, Fundación Universitaria Española, 2001 , p. 450.

28. Francisco Antonio de la Cruz, op. cit., f. $4 \mathrm{v}$.

29. Ibid., f. 5v.

30. Ibid., f. $6 \mathrm{v}$.

31. Ibid., f. $5 \mathrm{v}$.

32. Loc. cit. 
Manuel era celoso pastor del rebaño estudiantil "aquel no perder de vista las aulas, aquel no faltar a todas las literarias funciones, aquel no dejar de mano las conferencias, asistiendo y presidiendo las de las facultades mayores" ${ }^{33}$. El prelado andaba fuera de sí, llevado por un furor divino, inquisitivo, en plenas aulas: "no sólo bajaba a las aulas de los Gramáticos, sino que visitaba con mayor frecuencia el general de Teología a investigar solícito cuáles y cuántos eran los cursantes del idioma mexicano" ${ }^{34}$. Le asombra al orador "icon qué fervor encargaba el cuidado de ese estudio!, icon qué espíritu solicitaba la asistencia este empleo!" 35 . No es raro, entonces, que instados por semejante calor "influía este celo en los corazones de los estudiantes... con la brevedad con la que se consumaban los sujetos en un idioma tan difícil, como extraño" es que, según referencia, el calor divino daba don de lenguas. Los alumnos del colegio sorprendían a propios y extraños en el uso de la lengua mexicana "salen a predicar a todo el orbe en varias lenguas, y distintos idiomas, con tal perfección, que los que oían sus palabras juzgaban admirados que eran nacidos en las incultas naciones y bárbaros climas donde se hablaban aquellas extrañas y difíciles lenguas" 36 .

Un aspecto muy importante dentro dela concepción del sermón fúnebre era que debía tener un marcado carácter no sólo panegírico, sino también un fuerte nexo con la comunidad y sus virtudes. Como si sólo el cuerpo de aquel ausente hubiera partido, pero sus virtudes fueran comunitarias, compartidas por todos. En el caso de estos textos de exequias, habitualmente la forma de cierre o de identificar que ya era inminente el final es la parte denominada epílogo y la posterior exhortación a los presentes ${ }^{37}$. El sol llegó a su ocaso, pero llega así a su verdadero lugar, el cielo, "que es la patria verdadera de las permanentes luces, el centro seguro de las eternas claridades" ${ }^{38}$.

\section{Loc. cit.}

34. Ibid., f. $6 \mathrm{v}$.

35. Loc. cit.

36. Loc. cit.

37. Félix Herrero Salgado, op. cit., pp. 453-465.

38. Francisco Antonio de la Cruz, op. cit., f. $7 \mathrm{r}-7 \mathrm{v}$. 
Hacia finales del siglo XVII, los sermones tenían un tono triunfalista que pregonaba a la ciudad de origen por encima de las demás; un fenómeno de marcado "criollismo", que los fallecidos en olor de santidad hacían palpable, pues el occiso era "hijo pródigo" de ese lugar, que había sido elegido por la trascendencia para mostrar sus virtudes más señaladas de esta tierra predestinada, en este caso, la Angelópolis.

Resulta claro que estos documentos no son para nosotros lo que fueron en su tiempo. Veamos:

La religión entre los novohispanos, por otra parte, fue no sólo mucho más importante de lo que ha sido para los mexicanos modernos, sino una religión diferente en densidad, en profundidad, en episodios... buena parte de sus letras se consagró a ceremonias, fiestas, oraciones, concursos y situaciones de la Iglesia. Son los textos que más se escribieron, leyeron y escucharon, y los que menos entendemos, porque la religión moderna no sabe leerlos: vemos dogmas o anécdotas, ideas o creencias culturales en lo que era cultura viva... para la mayoría de los novohispanos lo más histórico que les ocurría era lo ultraterreno ${ }^{39}$.

En ellos confluye una gran variedad de materias históricas, religiosas, literarias, sociales, etc., y aparecen a nuestros ojos desprovistos de todo el entorno social que les dio vida. Hacia el siglo XVIII, la práctica ampulosa del sermón estaba agotada y por esa razón aparecieron obras que satirizaban no sólo la prédica, sino la formación de los religiosos dedicados a ella, como finalmente se vio en La historia del predicador Fray Gerundio de Campazas, alias Zotes, del padre José Francisco de Isla y Rojo. Curiosamente, hacia el XVIII se inicia un cambio y se abandonan los excesos que el Barroco traía consigo.

El sermón se mantiene como un género longevo, pues ha estado presente en la actividad humana desde hace más de dos mil años.

39. José Joaquín Blanco, Prólogo a El lector novohispano. México, Cal y Arena, 1996, pp. 21-22. 
Sin embargo, el estudio de sus particularidades, recursos, valores y limitaciones arroja interesante información que indaga las visiones del mundo del siglo XVII. Estos textos son ventanas verbales, de las pocas que nos quedan hoy en día para conocer la maravilla novohispana. Ventanas artificiosas y monumentales si se quiere, sin embargo, el lenguaje pleno de retórica ${ }^{40}$ del sermón fúnebre debe ser un reto a descifrar más que un factor disuasorio para el investigador. Una de las necesidades que han guiado mi estudio de tales documentos ha sido; primero, darles un lugar dentro de la cultura literaria de la Nueva España, basándome en la creencia de que este tipo de manifestaciones muestra el modo de articulación de la sociedad virreinal y su pensamiento, teñido de referencias invisibles e interrelaciones significativas, todas ellas presentes y simultáneamente reales.

40. Precisamente, éste es uno de los rasgos por los que se suelen dejar de lado el estudio de las artes oratorias, por su clara tendencia a la falsedad discursiva, al cliché y a la mera técnica en el uso efectivo del lenguaje: "Podríamos concebir la retórica como un saber progresivamente sistematizado que, alejándose de su origen en la plaza pública... se convierte lentamente en un metalenguaje, un tecné del discurso abstracto y teóricamente considerado, independiente de cualquier referente real, llegando a formar un corpus ideal que contempla con distancia todo tipo de realizaciones pragmáticas"; Fernando Rodríguez de la Flor y Linda Báez Rubí, "Retórica y Conquista", en Barroco: representación e ideología del Mundo Hispánico. Madrid, Cátedra, 2002, p. 301. 